$\S=-1$

\title{
An overview of passive and active drag reduction methods for bluff body of road vehicles
}

\author{
Lay Chuan Eun, Azmin Shakrine Mohd Rafie*, Surjatin Wiriadidjaja, Omar Faruqi Marzuki \\ Department of Aerospace Engineering, Faculty of Engineering, Universiti Putra Malaysia, 43400 Serdang, Selangor, Malaysia \\ *Corresponding author E-mail: shakrine@upm.edu.my
}

\begin{abstract}
This paper is an overview of results done on bluff body road vehicle's base drag reduction either by experimental or numerical methods. Two categories of devices are divided that prove certain degrees of effectiveness in reducing the base drag, namely passive and active. The reduction of drag coefficient achieved in existing research ranging from 5\% to 50\%, which varies for each method and device. However, the higher the achieved drag reduction is, the greater the compensation required is. The compensation comes in various forms to achieve the desirable drag reduction. For passive drag reduction, hump shaped bluff body with boat-tail shows significant drag reduction by $50.9 \%$ compared to the other methods. Meanwhile, one of the potential of active drag reductions is by utilizing rotating cylinder. The rotating can reduce the drag on the bluff body by influencing the separation of boundary layer. The drag can be further reduced by enhancing the rotating cylinder with surface roughness and rotation speed. A notable $23 \%$ reduction of drag coefficient using rough surface on bluff body vehicle's is achieved compared to the smooth surface.
\end{abstract}

Keywords: base drag reduction, bluff body vehicle, rotating cylinder

\section{Introduction}

Fuel efficiency of vehicle is one of the main interests in the automotive industry due to it being as one the main factors that affect the operating cost of transportation. Aside from engine efficiency and performance, drag reduction is one of the main contributors to vehicle's fuel efficiency. The aerodynamic performance has been taken into account in car designs but for heavy road vehicles such as tractor-trailer, major design change to achieve high aerodynamic performance is impossible. This is mainly because it will affect cargo capacity since, to achieve a high aerodynamic performance, tapered shape and slander body is required for the vehicles to minimize the pressure drag.

When a bluff body travels at a speed, the void created at the back of the body will cause a low pressure region. This phenomenon is causing the higher pressure air from the surrounding to flow into the region to fill the void, known as the aerodynamic wake. This creates a form of drag known as pressure drag or commonly called base drag. A constant speed driven bluff body vehicles on a flat level road will use up to $40 \%$ of the fuel energy to overcome aerodynamic drag and $45 \%$ to overcome rolling resistance, with $5 \%$ is used up to drive the gear and loses [1]. Moreover, an experiment study on a truck model that is scaled $1 / 32$ shows that drag coefficient increases to $15.8 \%$ with the trailer attached [2].

As aerodynamic drag is a factor for fuel consumption, base drag is one of main contributors to the aerodynamic drag. Since the base drag takes place at rear end of the vehicles where the cargo space is located, major change to the vehicle design is not possible without affecting the volume and capacity of the cargo. Many research have been done to reduce the base drag and this paper discusses them by dividing them into two categories: passive and active drag reduction applications for bluff bodies [3]. This paper highlights the passive and active drag reduction methods for bluff body of road vehicles, and also provides the initial understanding regarding the base drag reduction as each method gives a different performance improvement to the bluff body road vehicles.

\section{Passive drag reduction}

The well-known types of passive drag reduction method used for bluff bodies can be divided into cab-roof fairing, boat-tail, hump, curved boat-tail flaps, Ahmed body, base bleed, vertical splinter plate and base cavity. Cab-roof fairing reduced the drag by defecting the incoming air from the trailer [4]. This is done by having half-triangle deflector shape attached on the vehicle roof. There are several ways to improve the cab-roof fairing and one of them is through biomimicry approach. Kim et al. [4] utilizes the sea lion head shaped as a defector to reduce the drag coefficient to around $22.4 \%$.

On the other hand, boat-tail is an extension structure attached at the rear end of typical squared shaped vehicle. Boat-tail has certain degrees of curvature inward to the centre, behind the vehicle's body. The function is to redirect the airflow inward after the trailing edge and delay the flow separation [5]. Numerous research on boat-tailing method in reducing bluff bodies vehicle rear end pressure drag have already started before 1970. Investigation of drag reduction by boat-tailing shows that there is a significant pressure drop slightly before and after the boat-tail. This is claimed to be due to the flow acceleration outside the boundary layer due to the boat-tail's convex curvature of the streamlines [6]. This pressure reduction causes more drag to act on the surface but this drag is insignificant as numerical analysis has concluded that by the aid of the boat-tail, it is able to lower the drag coefficient up to $30 \%$ [7, 8]. Reubush [6] has stated that a good performance boat-tail has the length and the ratio between the final and initial diameter that 
maintains the boundary layer attached up the base. Mair [9] shows that geometrical modifications such as boat-tail, which consists of the body cross-section reduction in gradual pattern before the base, may lead to flow and pressure changes. The geometry of the boattail and drag coefficient versus the length over body width ratio can be seen in Figure 1. An experimental and numerical investigation by Burton et al. [10] have been conducted for zero yaw condition with Reynolds Number, $\operatorname{Re}=850,000$ and it identifies $15^{\circ}$ as the optimum boat-tail angle to maintain the attachment of the majority of the airflow. In addition, the boat-tail can be modified with a lower inclined air deflector with a slant angle of $45^{\circ}$ that shows small reduction of drag coefficient (i.e. 9.02\%) [11].

Furthermore, the hump is a curvature surface shaped that is added onto the original flat surface of the bluff bodies. The application of hump at four side and short boat-tail enables the drag to reduce up to $50.9 \%$ compared to that with only boat-tail, which is effectively up by $15 \%$ [12]. This technique is indeed effective in reducing the drag but it does require major modification of the vehicle geometry.

Meanwhile, Ahmed model has been introduced during 1980s [13]. The geometry is similar to the general model except with a slanted surface at the top of the body before the base. Investigation on the Ahmed model shows that, at the slant angle, $h$ of the slanted surface ranging between $12.5^{\circ}$ and $30^{\circ}$, separation bubbles are emanated and this results in the drag variation on the slanted surface. At above $30^{\circ}$, which is known as critical angle, the flow will separate above the slanted surface and the Ahmed model is no longer effective in reducing the drag as shown in Figure 2 [5]. The Ahmed model got more attention among researchers and more investigations have been done thereafter. One of the investigations is to overcome the problem of the separation bubbles. Several aerodynamic devices and modification are introduced including the flaps, vortex generators, arrays of circular cylinders and rounded edge [5, 14-17]. Aside from that, a deflector is tested on the Ahmed model with the angle ranging from $-25^{\circ}$ to $50^{\circ}$. The result shows a drag reduction of up to $9 \%$ and it is stated that the amount of drag reduced depends on the deflector angle [18]. Moreover, Hanfeng et al. [19] have obtained similar findings by using a combination of deflectors and the Ahmed body shape that reduces the drag up to $10.9 \%$.

Vertical splitter plate, in the meantime, is an extension of the flat structure mounted at the rear end of the vehicle at specific distance. It has been seen that the application of the plates manages to reduce the total drag by $18 \%$ as the plate disturbs the formation of a recirculation bubble $[7,20]$. However, applying the vertical splitter plate at the rear end of the square back is not practical since the size required is too large. Lastly, a base cavity is an extension flat structure from the four edges downstream of the vehicle that reduces the sudden pressure drop at the rear end of the vehicle and thus reducing the pressure drag [5, 21-24].

Although various ideas of boat-tailing and devices have been introduced to reduce the pressure drag, this application will cause a significant increase of the vehicle's length, which is impractical and violates the standard size and weight regulations. This is because an average size boat-tail requires the extension of the vehicle's length from $0.3 \mathrm{~m}$ to $0.6 \mathrm{~m}$, which will be incompatible with the standard size and weight regulations [25]. Therefore, to overcome the excessive length of initial boat-tail design, many different designs of shorter boat-tail are introduced into the market and remarkably, these devices are still able to provide significant drag reduction of average between 5\% to $10 \%$ though they are shorter in length. Along the way, numerous studies and investigation are carried out either numerical or experimental investigations, which show that the boat-tailing method provides a significant improvement on aerodynamic performance and fuel efficiency [10, 26-31].

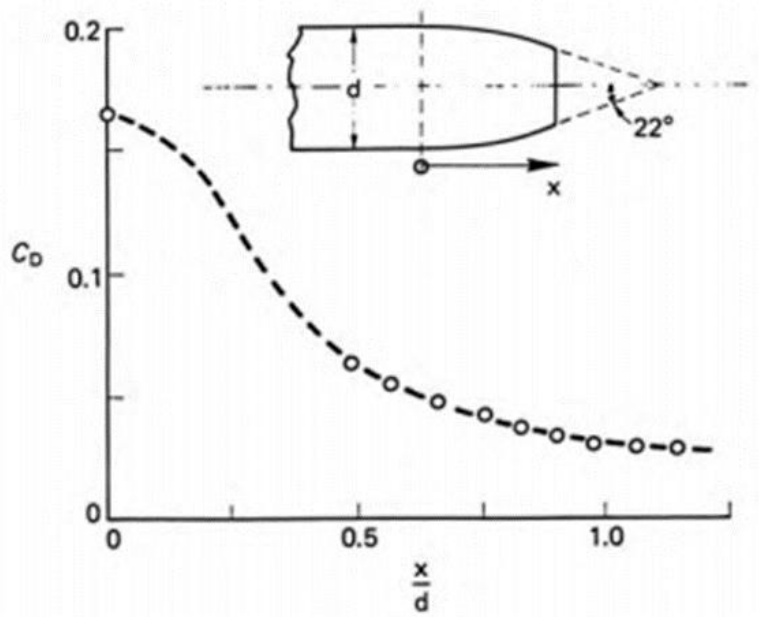

Fig. 1: Effect of boat-tailing drag coefficient, $C_{D}$ versus length over width ratio, $x / d[9]$
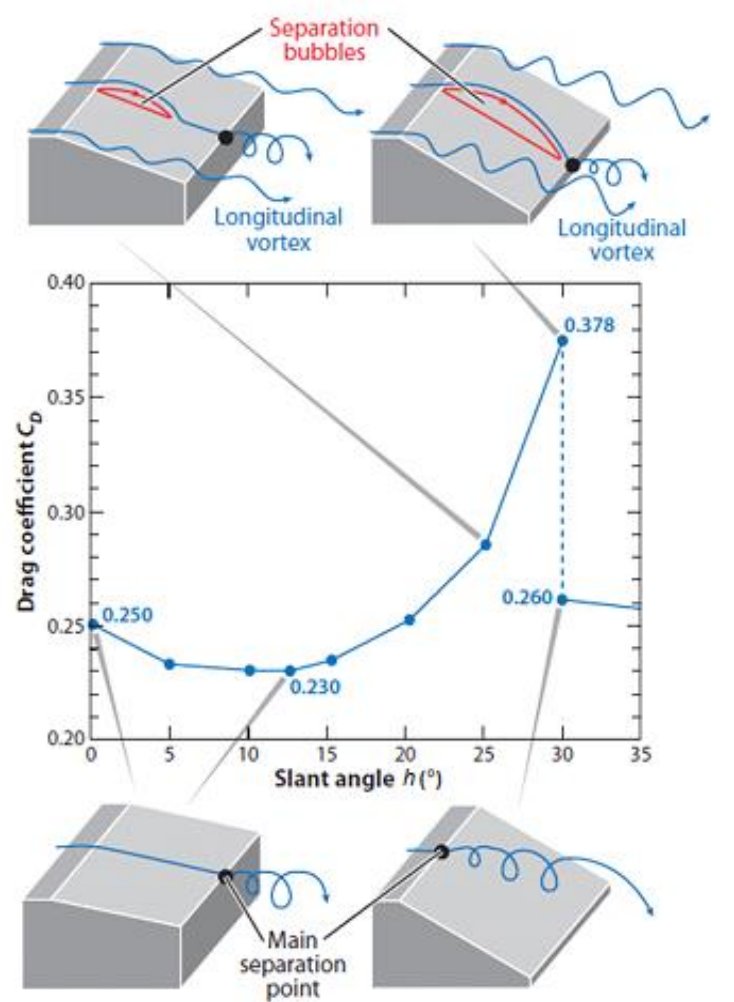

Fig. 2: Ahmed model drag coefficient, $C_{D}$ versus slant angle, $h$ [5]

\section{Active drag reduction}

The most known active drag reduction methods for bluff bodies is base bleed and moving surface. The base bleed technique is tested in few researches to monitor the drag reduction by introducing the active flow at the rear end of the vehicle. The active flow method by using the Coanda jet with jet speed of 1.5 times the free stream velocity has been numerically tested and the result shows the reduction of drag up to $50 \%$ from the total drag. However, the energy required to generate the Coanda jet is not taken into account during this experiment [7]. On the other hand, the similar studies conducted show that, for this technique to be applicable on actual vehicles, a large amount of mass flow rate is required [32-34]. 


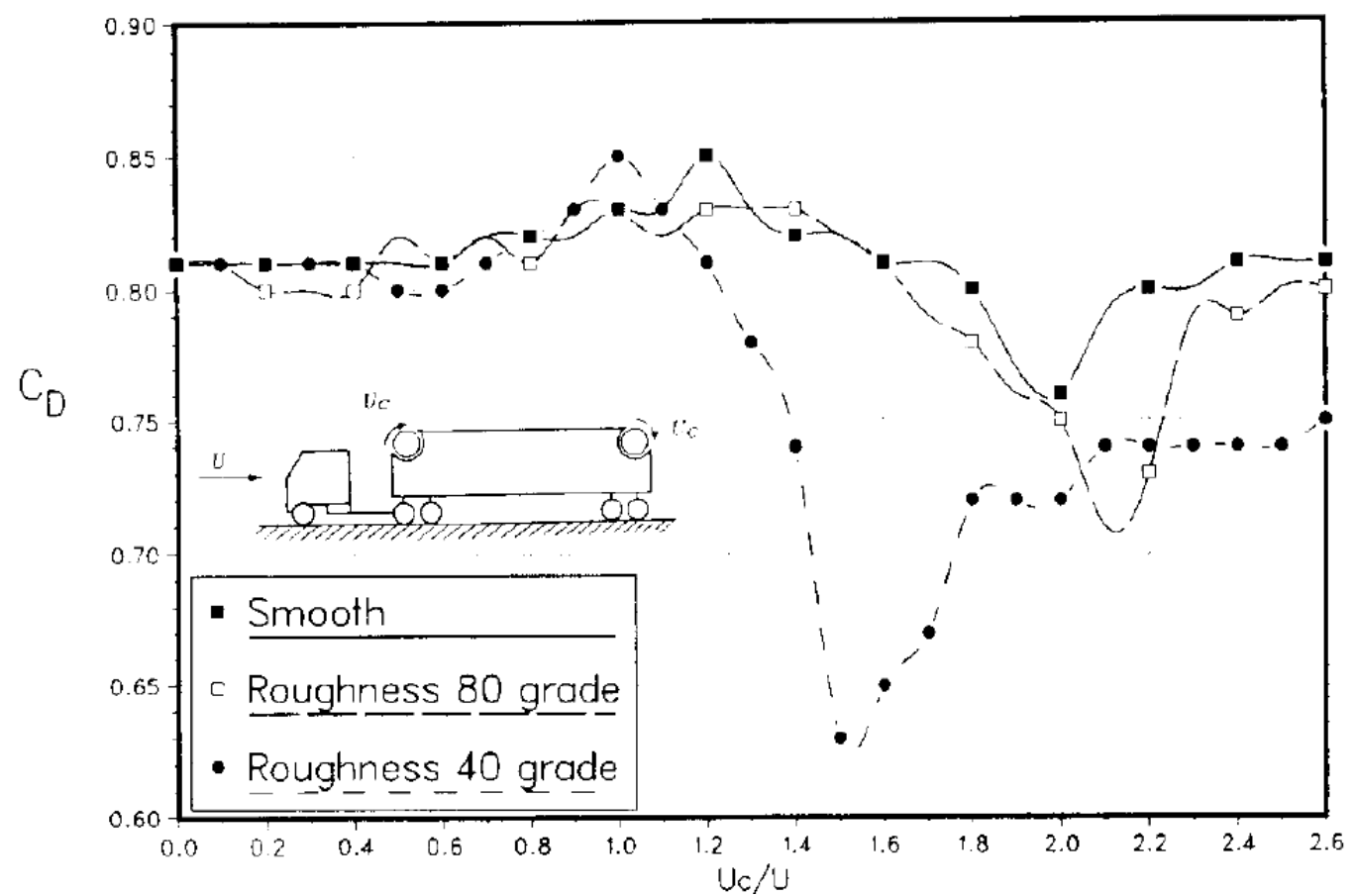

Fig. 3: Effect of the moving surface boundary-layer control on the drag coefficient of a tractor-trailer truck configuration [36]

The momentum injection method by moving surface is a boundary layer control technique that is used to delay the separation of the boundary layer at the aft of the vehicle body [35-41]. The moving surface is provided by a rotating cylinder that rotates in the direction of the airflow. The speed of the rotating cylinder plays a big role in injecting momentum to the air flow to energize the boundary layer and thus delaying the flow separation and minimizing the turbulence flow, which is one of the causes for the base drag [35]. One of the main parameters that is affecting the rotating cylinder performance is the velocity ratio, which is the ratio of the rotating cylinder surface speed $\left(U_{C}\right)$ to the incoming freestream velocity ( $U$ ) [36, 42]. Modi et al. [36] have found that the roughness of the cylinder also has significant effect on the performance of the rotating cylinder in reducing the base drag. An experimental study has been conducted using smooth, roughness grade 40 and roughness grade 80 surfaces for the rotating cylinder to the reduction of drag coefficient of the truck model. The model is fitted with the rotating cylinder at both leading edge and trailing edge with the length over height ratio $(L / H)$ of 3.75 and velocity ratio, $U_{C} / U$ ranging from 0 to 2.6. The result shows that the drag coefficient drop 23\% to 0.625 from 0.81 at $U_{C} U=1.5$ for roughness grade 40 cylinder as compared to truck model without rotating cylinder as shown in Figure 3 [36].

\section{Conclusion}

Among all the methods demonstrated in the studies, passive drag reduction hump and boat-tail flap and active drag reduction base bleed method have shown the highest percentage of drag reduction that are $50.9 \%$ and $50 \%$ reduction, respectively. However, these two methods are the least practical to be applied in the commercial vehicles as the hump and boat-tail flap require huge add-on to the vehicle dimension while the base bleed requires a huge amount of energy to generate enough mass of airflow to achieve the desirable drag reduction. The boat-tail method in commercial vehicle might be applicable as it offers a considerable amount of drag reduction that can be as high as $30 \%$ reduction if only the addition dimension of the boat-tail is not an issue. Meanwhile, rotating cylinder shows good potential for future studies with the highest drag reduction achieved with least dimension modification on the vehicle's body and energy required compared to the Ahmed body and vertical splitter plate. Furthermore, there is great potential in rotat- ing cylinder application by attachment to the vehicle body without shaped modifications on the bluff body. Overall, the studies of the base drag reduction have shown a significant result in reducing the base drag, either numerically or experimentally. More studies can still be done in the prospective areas by combinations of different methods and different variables.

\section{Acknowledgement}

The authors acknowledge the support of the Universiti Putra Malaysia (UPM) to this study through Putra Grant No. 9531600.

\section{References}

[1] Christensen J, Glaeser KP, Shelton T, Moore B \& Aarts L (2010), Innovation in truck technologies. International Transport Forum

[2] Bayındırlı C, Akansu YE \& Salman MS (2016), The determination of aerodynamic drag coefficient of truck and trailer model by wind tunnel tests. International Journal of Automotive Engineering and Technologies 5(2), 53-60

[3] Altaf A, Omar AA \& Asrar W (2014), Review of passive drag reduction techniques for bluff road vehicles. IIUM Engineering Journal 15(1), 61-69

[4] Kim JJ, Hong J \& Lee SJ (2017), Bio-inspired cab-roof fairing of heavy vehicles for enhancing drag reduction and driving stability. International Journal of Mechanical Sciences 131-132, 868-879

[5] Choi H, Lee J \& Park H (2014), Aerodynamics of heavy vehicles. Annual Review of Fluid Mechanics 46(1), 441-468

[6] Reubush DE (1976), Effect of reynolds number on boattail drag. Journal of Aircraft 13, 334-337

[7] Khalighi B, Chen KH \& Iaccarino G (2012), Study of drag reduction devices for a square back vehicle configuration using RANS CFD simulations. SME 2012 Fluids Engineering Division Summer Meeting

[8] Khalighi B, Chen K \& Iaccarino G (2012), Unsteady aerodynamic flow investigation around a simplified square-back road vehicle with drag reduction devices. Journal of Fluids Engineering 134(6), 061101

[9] Mair WA (1969), Reduction of base drag by boat-tailed afterbodies in low-speed flow. Aeronautical Quarterly 20, 307-320

[10] Burton D, Nazarinia M, Sheridan J \& Parkin D (2011), Optimisation of boat-tails for heavy vehicles. ASME-JSME-KSME 2011 Joint Fluids Engineering Conference 
[11] Lee EJ \& Lee SJ (2017), Drag reduction of a heavy vehicle using a modified boat tail with lower inclined air deflector. Journal of Visualization 20 (4), 743-752

[12] Hsu F \& Davis RL (2010), Drag reduction of tractor-trailers using optimized add-on devices. Journal of Fluids Engineering 132(8), 084504

[13] Ahmed SR, Ramm G \& Faitin G (1984), Some salient features of the time-averaged ground vehicle wake. SAE Technical Paper Series, 840300

[14] Pujals G, Depardon S \& Cossu C (2010), Drag reduction of a 3D bluff body using coherent streamwise streaks. Experiments in Fluids 49(5), 1085-1094

[15] Thacker A, Aubrun S, Leroy A \& Devinant P (2012), Effects of suppressing the 3D separation on the rear slant on the flow structures around an Ahmed body. Journal of Wind Engineering and Industrial Aerodynamics 107-108, 237-243

[16] Beaudoin J \& Aider J (2008), Drag and lift reduction of a 3D bluff body using flaps. Experiments in Fluids 44(4), 491-501

[17] Aider J, Beaudoin J \& Wesfreid J (2010), Drag and lift reduction of a 3D bluff-body using active vortex generators. Experiments in Fluids 48(5), 771-789

[18] Fourrié G, Keirsbulck L, Labraga L \& Gilliéron P (2011), Bluffbody drag reduction using a deflector. Experiments in Fluids 50(2), 385-395

[19] Hanfeng W, Yu Z, Chao C \& Xuhui H (2016), Aerodynamic drag reduction of an Ahmed body based on deflectors. Journal of Wind Engineering and Industrial Aerodynamics 148, 34-44

[20] Gillieron P \& Kourta A (2010), Aerodynamic drag reduction by vertical splitter plates. Experiments in Fluids 48(1), 1-16

[21] Balkanyi S, Bernal L \& Khalighi B (2002), Analysis of the near wake of bluff bodies in ground proximity. ASME 2002 International Mechanical Engineering Congress and Exposition

[22] Khalighi B, Zhang S, Koromilas C, Balkanyi S, et al. (2001), Experimental and computational study of unsteady wake flow behind a bluff body with a drag reduction device. SAE Technical Paper, 2001-01-1042

[23] Verzicco R, Fatica M, Iaccarino G, Moin P \& Khalighi B (2002), Large eddy simulation of a road vehicle with drag reduction devices. AIAA Journal 40(12), 2447-2455

[24] Yi W (2007), Drag reduction of a three-dimensional car model using passive control device. Seoul Natl. Univ.

[25] Woodrooffe J \& Dahlberg E (2013), Regulatory options for improving aerodynamic performance of commercial vehicles. SAE Technical Paper, 2013-01-2416

[26] Sharma R, Chadwik D \& Haines J (2008), Aerodynamics of an intercity bus. Journal of Wind and Structures $11,257-273$

[27] Surcel M, Michaelsen J \& Provencher Y (2008), Track-test evaluation of aerodynamic drag reducing measures for class 8 tractortrailers. SAE Technical Paper, 2008-01-2600

[28] Johansson M, Sheridan J \& Fredriksson S (2010), The effect of oscillatory boat-tail flaps on the near wake of a prototypical heavy vehicle. 3rd Joint US-European Fluids Engineering Summer Meeting

[29] Landman D, Cragun M, McCormick M \& Wood R (2011), Drag reduction of a modern straight truck. SAE Int. J. Commer. Veh.

[30] Cooper K (2012), Wind tunnel and track tests of Class 8 tractors pulling single and tandem trailers fitted with side skirts and boattails. SAE Int. J. Commer. Veh.

[31] Burton D, McArthur D, Sheridan J \& Thompson M (2013), Contribution of add-on components to the aerodynamic drag of a cab-over truck-trailer combination vehicle. SAE Int. J. Commer. Veh.

[32] Englar R (2001), Advanced aerodynamic devices to improve the performance, economics, handling and safety of heavy vehicles. SAE Technical Paper, 2001-01-2072

[33] Howell J, Sheppard A \& Blakemore A (2003), Aerodynamic drag reduction for a simple bluff body using base bleed. SAE Technical Paper, 2003-01-0995

[34] Littlewood RP \& Passmore MA (2012), Aerodynamic drag reduction of a simplified squareback vehicle using steady blowing. $E x$ periments in Fluids 53(2), 519-529

[35] Modi VJ (1997), Moving surface boundary-layer control: A review. Journal of Fluid and Structure 11(6), 627-663

[36] Modi VJ, Fernando MSUK \& Yokimizo T (1991), Moving surface boundary-layer control as applied to two and three dimensional bodies. Journal of Aircraft 28(1), 104-112

[37] Modi VJ, Fernando MSUK \& Yokimizo T (1991), Moving surface boundary-layer control: studies with buff bodies and application. AIAA Journal 29, 1400-1406
[38] Modi VJ, Ying B \& Yokimizo T (1991), Boundary-layer control of buff bodies through momentum injection. SAE Journal of Commercial Vehicles 99, 778-794

[39] Modi VJ, Ying B \& Yokimizo T (1991), An approach to design of the next generation of fuel efficient truck through aerodynamic drag reduction. ASME Winter Annual Meeting

[40] Modi VJ, Ying B \& Yokimizo T (1992), Effect of momentum injection on the aerodynamic of several bluff bodies. Journal of Wind Engineering and Industrial Aerodynamics 41, 713-714

[41] Beaudoin J, Cadot O, Aider J \& Wesfreid J (2006), Drag reduction of a bluff body using adaptive control methods. Physics of Fluids 18,085107

[42] Seifert J (2012), A review of the Magnus effect in aeronautics. Progress in Aerospace Sciences 55, 17-45 